\title{
Potential significance of the regucalcin gene in human carcinoma
}

\author{
Masayoshi Yamaguchi* \\ Department of Hematology and Medical Oncology, Emory University School of Medicine, Atlanta, USA
}

I am pleased to prepare inaugural editorial for a new Journal "Integrative Cancer Science and Therapeutics (ICST)". ICST is an open access, international peer reviewed journal that enlightens the cancer research community by providing an insight on breakthrough discoveries that cover integrative fields of basic and clinical cancer research. Cell proliferation is mediated through various intracellular signaling transductions that are stimulated by many hormone and cytokines. Enhanced cell proliferation may lead to carcinogenesis. However, mechanism of carcinogenesis is complexity and its therapy is not established. Cancer is a pathological condition, where assemblage of cells displays uncontrolled growth, invasion and metastasis. Cancer medicine is based on diagnosis, therapy and post therapy procedure. Cancer therapeutics involves various pathological, pharmacological, medical and clinical approaches with several implications. ICST will contribute to development of cancer sciences and therapy.

Regucalcin is a novel suppressor protein in cell signaling discovered by the author of this editorial, Yamaguchi, in 1978 [1,2]. Regucalcin is demonstrated to play a multifunctional role in cell regulation in various types of cell and tissues [3,4]. Regucalcin is predominantly expressed in liver and kidney tissues. Interestingly, overexpression of the regucalcin gene was found to suppress liver cell proliferation and carcinogenesis in animal models [3-7]. Moreover, there is growing evidence that the regucalcin gene expression is uniquely suppressed in various human carcinoma tissues using analysis with multiple gene expression profiles and proteomics. Suppression of the regucalcin gene may lead to development of carcinogenesis. This editorial focuses a potential significance of regucalcin in the gene therapy for human hepatocarcinoma.

Hepatocellular carcinogenesis (HCC), the most common primary liver cancer, is one of the most prevalent malignant diseases worldwide, and the third most common causes of cancer-related death [8-10]. Globally, there are approximately 750,000 new cases of HCC reported per year. The incidence of HCC is increasingly in the United States and other developed countries. Moreover, features of HCC are an aggressive cancer with a dismal outcome largely due to metastasis and postsurgical recurrence. In most cases, HCC originates on a background of cirrhosis, a chronic and diffuse hepatic disease that result from continuous liver injury and regeneration [10]. Cirrhosis is present in approximately $80 \%-90 \%$ of HCC patients and constitutes the largest single risk factor. In cirrhotic liver, changes in fat metabolism associated with the activation of adipocyte-like pathways are thought to be involved in neoplastic transformation [10]. Increased hepatocyte turnover, inflammation and oxidative DNA damage is implicated in the pathogenesis of the liver disease including obesity, Type 2 diabetes, insulin resistant and nonalcoholic fatty liver disease. The prevalent risk factors for HCC are also the cause of liver cirrhosis that includes viral infections (hepatitis B and C) and alcohol consumption; further risk factors include tobacco smoking, exposure to aflatoxin B1 and vinyl chloride, diabetes, and genetic disorders, such as hemochromatosis and alpha-1 antitrypsin deficiency [11-15].

Hepatocarcinogenesis is a multistep process initiated by external stimuli that lead to genetic changes in hepatocytes or stem cells, resulting in proliferation, apoptosis, dysplasia and neoplasia. The majority of HCC cases are also related to chronic viral infections. Hepatitis B virus (HBV) DNA integrates into the host genome, inducing chromosome instability and insertional mutations that may activate various oncogenes, such as cyclin A [16-19]. Viral proteins, in particular X protein $(\mathrm{HBx})$, act as transactivators to upregulate several oncogenes (such as c-myc and c-jun) and transcriptional factors (such as nuclear factor- $\mathrm{kB}$ ) [20-22]. Additionally, HBx activates promoters of genes encoding interleukin-8 (IL-8), tumor necrosis factor (TNF), transforming growth factor (TGF)- $\beta$ and epidermal growth factor receptor (EGFR) [23]. HBx can also stimulate several signal transduction pathways, including the JAK/STAT, RAS/RAF/MAPK, and $\mathrm{Wnt} / \beta$-catenin pathways $[23,24]$. The contributions of hepatitis $\mathrm{C}$ virus (HCV) to hepatocarcinogenesis are mediated through viral proteins, including core, NS3 and NS5A proteins. HCV core protein can promote apoptosis or cell proliferation through interaction with p53 or upregulation of Wnt-1 at the transcriptional level [25-27].

The prognosis of advanced HCC remains poor in spite of the development of novel therapeutic strategies [28]. Traditional therapies are not effective for HCC and are too toxic for patients with cirrhosis. Transarterial chemoembolization and radioembolization are the main treatments for intermediate-stage HCC at the present time. Improved knowledge of the oncogenic processes and signaling pathways, which regulate tumor cell proliferation, differentiation, angiogenesis, invasion and metastatis, has led to the identification of several potential therapeutic targets that have driven the development of molecularly targeted therapies [28]. An ideal cancer target meets the following criteria: the target is relatively specific for cancer cells (not expressed or expressed at very low levels in normal cells but over expressed in cancer cells) [28]. Meanwhile, over expression of the target is associated with malignant biological phenotypes and/or poor prognosis; the target plays an essential role in cancer initiation and progression, and inhibition of expression or activity of the target induces growth suppression and/or

Correspondence to: Dr. Masayoshi Yamaguchi, Department of Hematology and Biomedical Oncology, Emory University School of Medicine, 1365 C Clifton Road, NE, Atlanta, GA 30322, USA, E-mail: yamamasa1155@yahoo.co.jp

Received: July 20, 2014; Accepted: July 22, 2014; Published: July 26, 2014 
apoptosis in cancer cells. The target is "drugable" as an enzyme (e.g., a kinase) or cell surface molecule (e.g., a membrane-bound receptor) that can be easily screened for small-molecule inhibitors or targeted by a specific antibody $[28,29]$. The only systemic therapy available for advanced HCC is based on the multikinase inhibitor sorafenib [29], which is the most effective therapeutic tool for advanced nonresectable HCC. The survival of patients with advanced HCC treated with sorafenib depends on the absence of liver dysfunction and on the status of the patient [30]. In the past few years, the use of sorafenib in combination with transarterial chemoembolization has improved survival rates in patients with advanced HCC. Recently, new perspectives in cancer treatment have appeared with the advent of microRNAs, a novel class of noncoding small RNAs [31].

Regucalcin may play a pivotal role in the suppression of hepatocarcinogenesis [5-7]. Regucalcin plays a role as a suppressor protein in various cell signal transductions $[3,4]$. The regucalcin gene is located on the $\mathrm{X}$ chromosome in consisting of seven exons and six introns [reviewed in Ref. 32]. Regucalcin and its gene (rgn) are identified in over 15 species consisting of regucalcin family, and the gene species are highly conserved in vertebrate species [32]. The regucalcin gene expression is regulated through various transcription factors (including AP-1, NF1-A1, RGPR-p117, $\beta$-catenin, SP1 and others), which are identified as the enhancer and suppressor, and this expression is regulated with hormonal stimulation and physiological state [32,33]. Regucalcin plays a pivotal role as a suppressor protein in various signal transductions to maintain cell homeostasis for stimuli, and it plays a multifunctional role in cell regulation through maintaining of intracellular $\mathrm{Ca}^{2+}$ homeostasis and suppressing of signal transduction in various cell types [reviewed in Refs. 3,4]. Interestingly, the cytoplasmic regucalcin was translocated into the nucleus that is mediated through protein kinase C-dependent signaling [31,34]. Nuclear regucalcin suppressed $\mathrm{Ca}^{2+}$-dependent and -independent protein kinases and protein phosphatases, $\mathrm{Ca}^{2+}$-activated endonuclease, and DNA and RNA synthesis in the nucleus [reviewed in Refs. 33].

Overexpression of regucalcin was found to play a role as a suppressor protein in cell proliferation that is mediated through various signaling stimulations in the cloned normal rat kidney proximal tubular epithelial NRK52E cells and the cloned rat hepatoma H4-II-E cells $[31,34,35]$. Regucalcin caused G1 and G2/M phase cell cycle arrest in these cells $[31,36]$. The anti-cell proliferation effect of regucalcin was not dependent on apoptosis; regucalcin suppresses apoptosis induced through multisignaling pathway [reviewed in Ref. 37]. Molecular mechanisms by which regucalcin suppress the promotion of cell proliferation was elucidated. Regucalcin directly inhibited the activities of various $\mathrm{Ca}^{2+} /$ calmodulin-dependent enzymes, protein kinases and protein phosphatases in the cytoplasm and nuclei $[3,4,33]$. Nuclear regucalcin was found to inhibit nuclear DNA and RNA synthesis and suppress the gene expression of $c-m y c, \mathrm{Ha}-\mathrm{ras}$, and $c-s r c$, a tumor-stimulator gene, and stimulate the gene expression of $p 53$ and $R b$, a tumor-suppressor gene $[33,38]$. Moreover, regucalcin was demonstrated to inhibit protein synthesis due to inhibiting aminoacyltRNA synthetase and stimulate protein degradation due to activating cysteinyl protease [reviewed in Refs. 3,4]. Thus, suppressive effects of regucalcin on cell proliferation are mediated through molecules with multi targets in liver cells $[3,4,33,37]$.

The gene expression of regucalcin was found to suppress in hepatocarcinogenesis. Liver regucalcin gene expression was suppressed at earlier periods of carcinogenesis in rats treated with diethylnitrosamine and then 2-acetylaminofluorene combined with partial hepatectomy, which induces an increase in proliferating cells [6]. The suppression of regucalcin protein expression was identified in proteomic analysis that was differentially expressed in the livers of rats fed 5\% ethanol for 1 and 3 months [7]. Liver regucalcin mRNA expression was suppressed by disorder of liver metabolism induced by administration of carbon tetrachloride [39], galactosamine [40] and phenobarbital [41] in rats. In addition, liver regucalcin level was reduced with the conditions of diabetes and ethanol ingestion [42] that lead to cirrhosis and HCC. The suppression of regucalcin gene expression may lead to the development of HCC. Noticeably, the regucalcin gene and its protein levels was found to specifically suppress in human HCC using analysis with multiple gene expression profiles and proteomics [43-47]. Suppressed regucalcin gene expression may lead to development of hepatocarcinogenesis.

Regucalcin may be a key molecule as a suppressor in cell proliferation and carcinogenesis in various types of cells and tissues. Overexpression of the regucalcin gene in cancer cells may reveal preventive and therapeutic effects on the development of carcinogenesis. Development of the regucalcin gene deliver system will be expected as a novel gene therapy in clinical aspects for cancer treatment.

\section{Acknowledgement}

Regucalcin studies of the author were supported by a Grant-in-Aid for Scientific Research (C) No.63571053, No.02671006, No.04671362, No.06672193, No.08672522, No.10672048, No.13672292 and No.17590063 from the Ministry of Education, Science, Sports, and Culture, Japan. Also, the author was awarded the Bounty of Encouragement Foundation in Pharmaceutical Research, Japan and the Bounty of the Yamanouchi Foundation for Research on Metabolic Disorders, Japan. This study was also supported by the Foundation for Biomedical Research on Regucalcin.

\section{References}

1. Yamaguchi M, Yamamoto T (1978) Purification of calcium binding substance from soluble fraction of normal rat liver. Chem Pharm Bull (Tokyo) 26: 19151918.[Crossref]

2. Yamaguchi $\mathrm{M}$ (1992) A novel $\mathrm{Ca}^{2+}$-binding protein regucalcin and calcium inhibition. Regulatory role in liver cell function. In: Calcium Inhibition. K Kohama (ed.), Japan Sci Soc Press, Tokyo and CRC Press, Boca Rato: 19-41.

3. Yamaguchi M (2005) Role of regucalcin in maintaining cell homeostasis and function (review). Int J Mol Med 15: 371-389. [Crossref]

4. Yamaguchi M (2011) Regucalcin and cell regulation: role as a suppressor protein in signal transduction. Mol Cell Biochem 353: 101-137. [Crossref]

5. Yamaguchi M (2013) Suppressive role of regucalcin in liver cell proliferation involvement in carcinogenesis. Cell Prolif 46: 243-253. [Crossref]

6. Suzuki S, Asamoto M, Tsujimura K, Shirai T (2004) Specific differences in gene expression profile revealed by cDNA microarray analysis of glutathione S-transferase placental form (GST-P) immunohistochemically positive rat liver foci and surrounding tissue. Carcinogenesis 25: 439-443. [Crossref]

7. Fernando H, Wiktorowicz JE, Soman KV, Kaphalia BS, Khan MF, et al. (2013) Liver proteomics in progressive alcoholic steatosis. Toxicol Appl Pharmacol 266: 470-480. [Crossref]

8. Jemal A, Center MM, DeSantis C, Ward EM (2010) Global patterns of cancer incidence and mortality rates and trends. Cancer Epidemiol Biomarkers Prev 19: 1893-1907. [Crossref]

9. Bosch FX, Ribes J, Díaz M, Cléries R (2004) Primary liver cancer: worldwide incidence and trends. Gastroenterology 127: S5-5S16. [Crossref]

10. Bosch FX, Ribes J, Cléries R, Díaz M (2005) Epidemiology of hepatocellular carcinoma. Clin Liver Dis 9: 191-211, v. [Crossref] 
11. Farazi PA, DePinho RA (2006) Hepatocellular carcinoma pathogenesis: from genes to environment. Nat Rev Cancer 6: 674-687. [Crossref]

12. Purohit V, Rapaka R, Kwon OS, Song BJ (2013) Roles of alcohol and tobacco exposure in the development of hepatocellular carcinoma. Life Sci 92: 3-9. [Crossref]

13. Wu HC, Santella R (2012) The role of aflatoxins in hepatocellular carcinoma. Hepat Mon 12: e7238. [Crossref]

14. Starley BQ, Calcagno CJ, Harrison SA (2010) Nonalcoholic fatty liver disease and hepatocellular carcinoma: a weighty connection. Hepatology 51: 1820-1832. [Crossref]

15. Dragani TA (2010) Risk of HCC: genetic heterogeneity and complex genetics. $J$ Hepatol 52: 252-257. [Crossref]

16. Terasaki S, Kaneko S, Kobayashi K, Nonomura A, Nakanuma Y (1998) Histological features predicting malignant transformation of nonmalignant hepatocellular nodules: a prospective study. Gastroenterology 115: 1216-1222. [Crossref]

17. Brechot C, Pourcel C, Louise A, Rain B, Tiollais P (1980) Presence of integrated hepatitis B virus DNA sequences in cellular DNA of human hepatocellular carcinoma. Nature 286: 533-535. [Crossref]

18. Minami M, Daimon Y, Mori K, Takashima H, Nakajima T, et al. (2005) Hepatitis $\mathrm{B}$ virus-related insertional mutagenesis in chronic hepatitis B patients as an early drastic genetic change leading to hepatocarcinogenesis. Oncogene 24: 43404348. [Crossref]

19. Wang J, Chenivesse X, Henglein B, Bréchot C (1990) Hepatitis B virus integration in a cyclin A gene in a hepatocellular carcinoma. Nature 343: 555-557. [Crossref]

20. Balsano C, Avantaggiati ML, Natoli G, De Marzio E, Will H, et al. (1991) Fulllength and truncated versions of the hepatitis B virus (HBV) X protein $(\mathrm{pX})$ transactivate the c- myc protooncogene at the transcriptional level. Biochem Biophys Res Commun 176: 985-992. [Crossref]

21. Twu JS, Lai MY, Chen DS, Robinson WS (1993) Activation of protooncogene c-jun by the X protein of hepatitis B virus. Virology 192: 346-350. [Crossref]

22. Chirillo P, Falco M, Puri PL, Artini M, Balsano C, et al. (1996) Hepatitis B virus pX activates NF-kappa B-dependent transcription through a Raf-independent pathway. J Virol 70: 641-646. [Crossref]

23. Andrisani OM, Barnabas S (1999) The transcriptional function of the hepatitis $\mathrm{B}$ virus $\mathrm{X}$ protein and its role in hepatocarcinogenesis (Review). Int J Oncol 15: 373-379. [Crossref]

24. Cha MY, Kim CM, Park YM, Ryu WS (2004) Hepatitis B virus X protein is essential for the activation of Wnt/beta-catenin signaling in hepatoma cells. Hepatology 39: 1683-1693. [Crossref]

25. Yamanaka T, Kodama T, Doi T (2002) Subcellular localization of HCV core protein regulates its ability for $\mathrm{p} 53$ activation and $\mathrm{p} 21$ suppression. Biochem Biophys Res Commun 294: 528-534. [Crossref]

26. Fukutomi T, Zhou Y, Kawai S, Eguchi H, Wands JR, et al. (2005) Hepatitis C virus core protein stimulates hepatocyte growth: correlation with upregulation of wnt-1 expression. Hepatology 41: 1096-1105. [Crossref]

27. Florese RH, Nagano-Fujii M, Iwanaga Y, Hidajat R, Hotta H (2002) Inhibition of protein synthesis by the nonstructural proteins NS4A and NS4B of hepatitis C virus. Virus Res 90: 119-131. [Crossref]

28. Shin JW, Chung YH (2013) Molecular targeted therapy for hepatocellular carcinoma: current and future. World J Gastroenterol 19: 6144-6155. [Crossref]

29. Wilhelm SM, Adnane L, Newell P, Villanueva A, Llovet JM, et al. (2008) Preclinical overview of sorafenib, a multikinase inhibitor that targets both Raf and VEGF and PDGF receptor tyrosine kinase signaling. Mol Cancer Ther 7: 3129-3140. [Crossref]

30. Singal AG, Marrero JA (2010) Recent advances in the treatment of hepatocellular carcinoma. Curr Opin Gastroenterol 26: 189-195. [Crossref]

31. Callegari E, Elamin BK, Sabbioni S, Gramantieri L, Negrini M (2013) Role of microRNAs in hepatocellular carcinoma: a clinical perspective. Onco Targets Ther 6: 1167-1178. [Crossref]
32. Yamaguchi M (2011) The transcriptional regulation of regucalcin gene expression. Mol Cell Biochem 346: 147-171. [Crossref]

33. Yamaguchi M (2013) Role of regucalcin in cell nuclear regulation: involvement as a transcription factor. Cell Tissue Res 354: 331-341. [Crossref]

34. Nakagawa T, Yamaguchi M (2006) Overexpression of regucalcin enhances its nuclear localization and suppresses L-type $\mathrm{Ca}^{2+}$ channel and calcium-sensing receptor mRNA expression in cloned normal rat kidney proximal tubular epithelial NRK52E cells. J Cell Biochem 99: 1064-1077. [Crossref]

35. Misawa H, Inagaki S, Yamaguchi M (2001) Suppression of cell proliferation and deoxyribonucleic acid synthesis in the cloned rat hepatoma H4-II-E cells overexpressing regucalcin. J Cell Biochem 84: 143-149. [Crossref]

36. Yamaguchi M, Daimon Y (2005) Overexpression of regucalcin suppresses cell proliferation in cloned rat hepatoma H4-II-E cells: involvement of intracellular signaling factors and cell cycle-related genes. J Cell Biochem 95: 1169-1177. [Crossref]

37. Yamaguchi M (2013) The anti-apoptotic effect of regucalcin is mediated through multisignaling pathways. Apoptosis 18: 1145-1153. [Crossref]

38. Tsurusaki Y, Yamaguchi M (2003) Overexpression of regucalcin modulates tumor-related gene expression in cloned rat hepatoma H4-II-E cells. $J$ Cell Biochem 90: 619-626. [Crossref]

39. Isogai M, Shimokawa N, Yamaguchi M (1994) Hepatic calcium-binding protein regucalcin in released into the serum of rats administered orally carbon tetrachloride. Mol Cell Biochem 131: 173-179. [Crossref]

40. Isogai M, Oishi K, Yamaguchi M (1994) Serum release of hepatic calciumbinding protein regucalcin by liver injury with galactosamine administration in rats. Mol Cell Biochem 136: 85-90. [Crossref]

41. Isogai M, Oishi K, Shimokawa N, Yamaguchi M (1994) Expression of hepatic calcium-binding protein regucalcin mRNA is decreased by phenobarbital administration in rats. Mol Cell Biochem 141: 15-19. [Crossref]

42. Isogai M, Kurota H, Yamaguchi M (1997) Hepatic calcium-binding protein regucalcin concentration is decreased by streptozotocin-diabetic state and ethanol ingestion in rats. Mol Cell Biochem 168: 67-72. [Crossref]

43. Graveel CR, Jatkoe T, Madore SJ, Holt AL, Farnham PJ (2001) Expression profiling and identification of novel genes in hepatocellular carcinomas. Oncogene 20: 2704-2712. [Crossref]

44. Choi JK, Choi JY, Kim DG, Choi DW, Kim BY, et al. (2004) Integrative analysis of multiple gene expression profiles applied to liver cancer study. FEBS Lett 565: 93-100. [Crossref]

45. Blanc JF, Lalanne C, Plomion C, Schmitter JM, Bathany K, et al. (2005) Proteomic analysis of differentially expressed proteins in hepatocellular carcinoma developed in patients with chronic viral hepatitis C. Proteomics 5:3778-3789. [Crossref]

46. Roy L, LaBoissière S, Abdou E, Thibault G, Hamel N, et al. (2010) Proteomic analysis of the transitional endoplasmic reticulum in hepatocellular carcinoma: An organelle perspective on cancer. Biochim Biophys Acta 1804: 1869-881. [Crossref]

47. Schröder PC, Segura V, Riezu JI, Sangro B, Mato JM, et al. (2011) A signature of six genes highlights defects on cell growth and specific metabolic pathways in murine and human hepatocellular carcinoma. Funct Integr Genomics 11: 419429. [Crossref]

Copyright: (C2014 Yamaguchi. This is an open-access article distributed under the terms of the Creative Commons Attribution License, which permits unrestricted use, distribution, and reproduction in any medium, provided the original author and source are credited. 